\title{
Bluecap: A geospatial model to assess regional economic-viability for mineral resource development
}

\author{
Stuart D.C. Walsh ${ }^{\text {a,* }}$, Stephen A. Northey ${ }^{\text {a }}$, David Huston ${ }^{\mathrm{b}}$, Mohan Yellishetty ${ }^{\mathrm{a}}$, \\ Karol Czarnota ${ }^{\mathrm{b}}$ \\ ${ }^{a}$ Department of Civil Engineering, Monash University, Melbourne, Australia \\ ${ }^{\mathrm{b}}$ Geoscience Australia, Canberra, Australia
}

\section{A R T I C L E I N F O}

\section{Keywords:}

Economic fairways

Mineral exploration

Integrated economic assessment

Numerical cost modelling

Mining

Mineral processing

\begin{abstract}
A B S T R A C T
Frontier mineral exploration is often exclusively focused on assessing geological potential without consideration for the economic viability of resource development. This strategy may overlook potentially prosperous zones for more geologically-favoured but financially-disadvantageous regions, or conversely, may introduce implicit biases against potential developments without due regard to underlying economies of scale or proximity to infrastructure. Accordingly, in this paper, we introduce a numerical model aimed at identifying economic fairways, $i$. $e$. areas permissive to mineral development from an economic perspective. The model, Bluecap, combines largescale infrastructure and geological datasets to conduct geospatial analysis of the economic-viability of mining operations across Australia.

We provide a detailed description of the inputs and assumptions that underlie the cost models employed in Bluecap, outlining the methods used to evaluate mining, processing, administrative and infrastructure expenses. We also describe the databases used by the model to evaluate available infrastructure, transportation distances and depth of cover. Finally, we present examples that demonstrate the use of the Bluecap model on regions around Mount Isa and the Murray Basin to verify its ability to evaluate commercially feasible mineral prospects. While the immediate utility of this model stands to benefit mineral explorers, its ability to map mineral economic fairways also provides an objective, evidence base to underpin government decision making with respect to position of new infrastructure and consideration of competing land use claims.
\end{abstract}

\section{Introduction}

In recent years, the majority of exploration expenditure in the Australian mining industry has been directed towards developments that expand the boundaries of existing reserve or resource estimates, or that identify nearfield satellite deposits (Australian Bureau of Statistics, 2019; Senior, 2019). However, longer-term there will be limitations to the success of such brownfield expansion. Thus considerable attention is being paid to efforts that enable cost-effective greenfield exploration to identify the major mineral deposits of the future, which will be necessary to supply the mineral and metal products required for future development (Ali et al., 2017).

Presently within Australia, significant research effort and funding aligned with the National Mineral Exploration Strategy (Geoscience Australia, 2017a,b) and the UNCOVER initiative (UNCOVER group, 2012) is being directed towards developing data sources and techniques to enable identification of mineral deposits under cover. For instance, Geoscience Australia's Exploring for the Future initiative is a $\$ 100.5$ million [AUD] program that is developing precompetitive datasets and data analytic tools, like Bluecap, to support exploration decision making (Geoscience Australia, 2019). These activities include extensive new geological, geochemical and geophysical data acquisition, processing and analysis to characterise the Australian lithosphere from the surface down to its base for the purpose of assessing resource potential through data interrogation and assimilation. These datasets and studies represent a dramatic shift in the resolution of understanding of Australia's geology under cover, and hence improve understanding of where mineral deposits may occur at depth.

The combination of greater diversity and sophistication in the exploration industry, changing market demands, and the need to develop deeper and more marginal prospects, calls for tools to help advise the industry on the economic viability of Australia's mineral

\footnotetext{
* Corresponding author.

E-mail address: stuart.walsh@monash.edu (S.D.C. Walsh).
} 

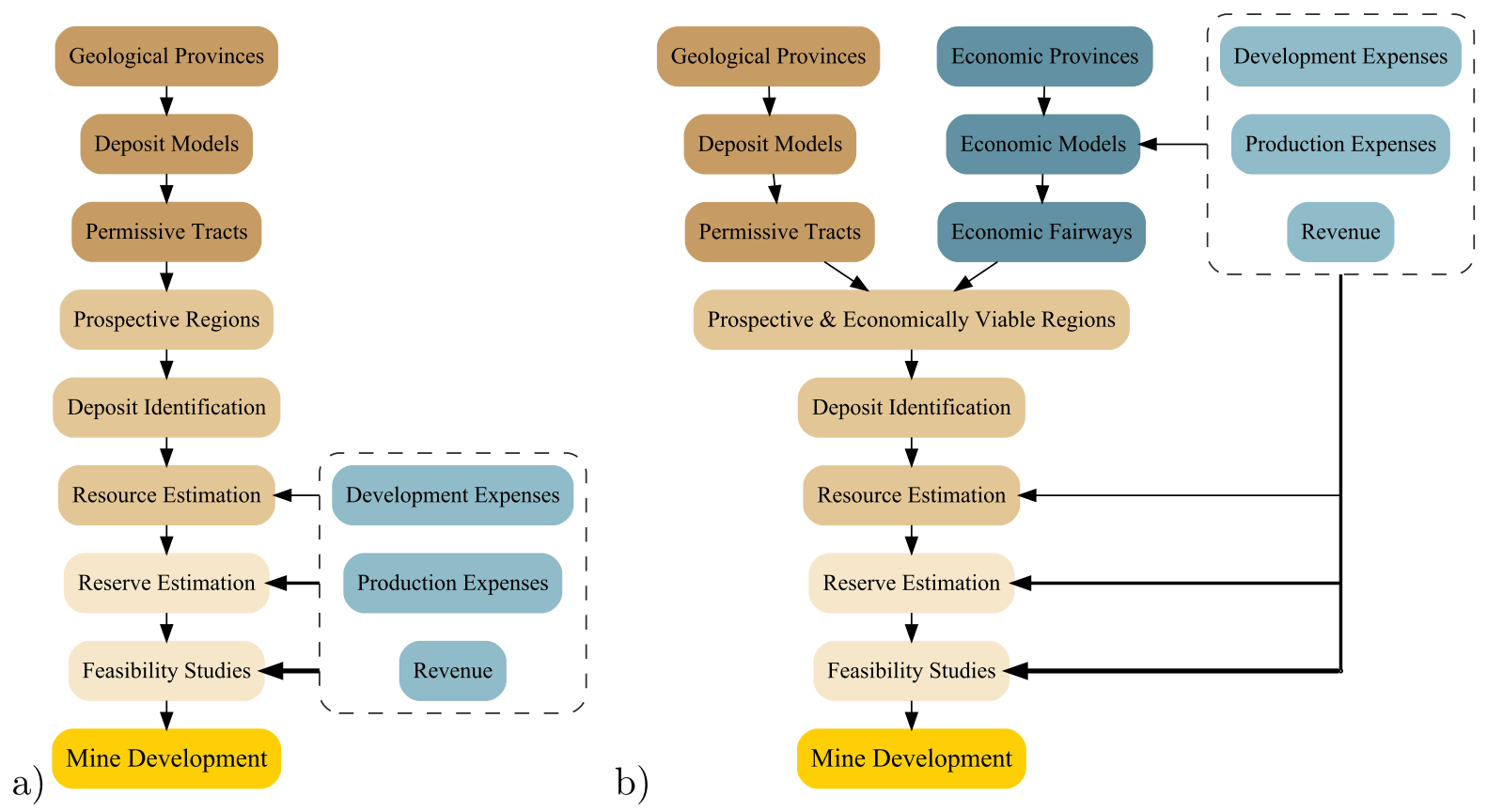

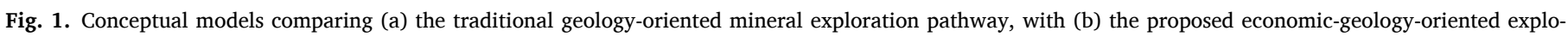
ration pathway, which introduces considerations of production costs and revenue earlier in the exploration process.

resources. While significant resources have been dedicated to assessing mineral potential from a geological standpoint, less attention has been given to how the economics of mineral resource development vary across Australia as a result of regional differences in geology and economic factors and the availability of development. For example, regional differences in availability and access to power, water and transportation infrastructure, distinct mineral royalty and taxation schemes, and major geological controls (such as depth of cover) influence the requirements for discovered mineral deposits to be considered economic. However, many of these differences are often not considered explicitly until late in traditional mineral exploration activities.

Fig. 1 delineates the major stages in identifying mineral deposits and developing them into active mining operations. The traditional geologyfocused mineral exploration pathway begins with an understanding of the regional geological context; followed by application of deposit models to determine the regions that are highly prospective for deposits; identifying and evaluating the characteristics of these deposits; then determining the relative economic viability of these deposits through evaluation of likely development expenses, production expenses and revenue generation. Under this approach, economic aspects are not analysed in detail until deposits have been identified and mineral resource definition, reserve definition and feasibility studies are being undertaken (Gandhi and Sarkar, 2016; Lilford and Minnitt, 2005). The limited existing approaches for valuation of under-explored mineral leases and properties that do attempt to account for factors such as cover depth and distance to infrastructure, such as the Lilford Techno Economic Matrix method (i.e. 'rand per hectare') (Lilford and Minnitt, 2002, 2005), do so in a highly subjective way without a strong conceptual formulation or transparent quantitative connection to realizable economic outcomes of individual deposits discovered in the future.

Therefore, we propose an alternative, economic-focused mineral exploration pathway that brings forward evaluation of the factors governing production costs and revenue earlier into the exploration process. This approach begins with an assessment of regional infrastructure and economic conditions, combined with coarse revenue and cost models to determine regional specific thresholds for a deposit's economic viability, identifying regions where unidentified mineral occurrences are most likely to meet these development constraints. This is later followed by exploration identifying and characterising mineral deposits within the economically advantageous sectors, determining the relative economic viability of identified deposits through detailed revenue and cost modelling. Essentially, this approach of understanding the regional economic fairways, where the thresholds for the characteristics (e.g. size, grade, etc.) of an economic deposit are lower, can be inserted mid-way into our exploration process to provide more informed assessments of regional prospectivity. This approach is particularly applicable in situations where substantial regional variations in cost drivers may exist, as is the case for Australia where distance to infrastructure and the depth of cover overlying potential mineral deposits varies substantially across the nation and within exploration tenements.

With these goals in mind, this paper describes the operation of a geospatial economic simulator - Bluecap - developed for Australian mining conditions. The aim of the simulator is to highlight regions of high development viability for the purpose of mineral exploration. Bluecap is designed to assist companies in focusing their efforts on regions more likely to generate commercially-viable mining prospects. The simulator uses empirical models to compare mining prospects across the continent. Due to its broad scope, it lacks the detailed information necessary for feasibility studies of individual projects, and as such, it should not be used as the sole basis for investment decisions. Nevertheless, by integrating both financial and geological considerations into the regional assessment, it provides a pre-scoping tool for improving consideration of economic factors within mineral exploration activities.

The Bluecap simulator considers distinct classes of hard-rock orebodies, as well as potential mining methods and processing systems. Mining and processing methods are costed via an approach similar to that developed by Camm (1991), using empirical models that reflect Australian mining conditions and practices in 2018. The choice of mining and processing method may be fixed by the user or selected automatically, based on an idealised ore-body model. The mining and processing cost models are coupled with infrastructure and financial models to evaluate the economic viability of mine locations across Australia. The following sections describe the calculations and assumptions involved in each component of the simulator. The use of the simulator is demonstrated through example case studies from the regions around Mount Isa and the Murray Basin. 


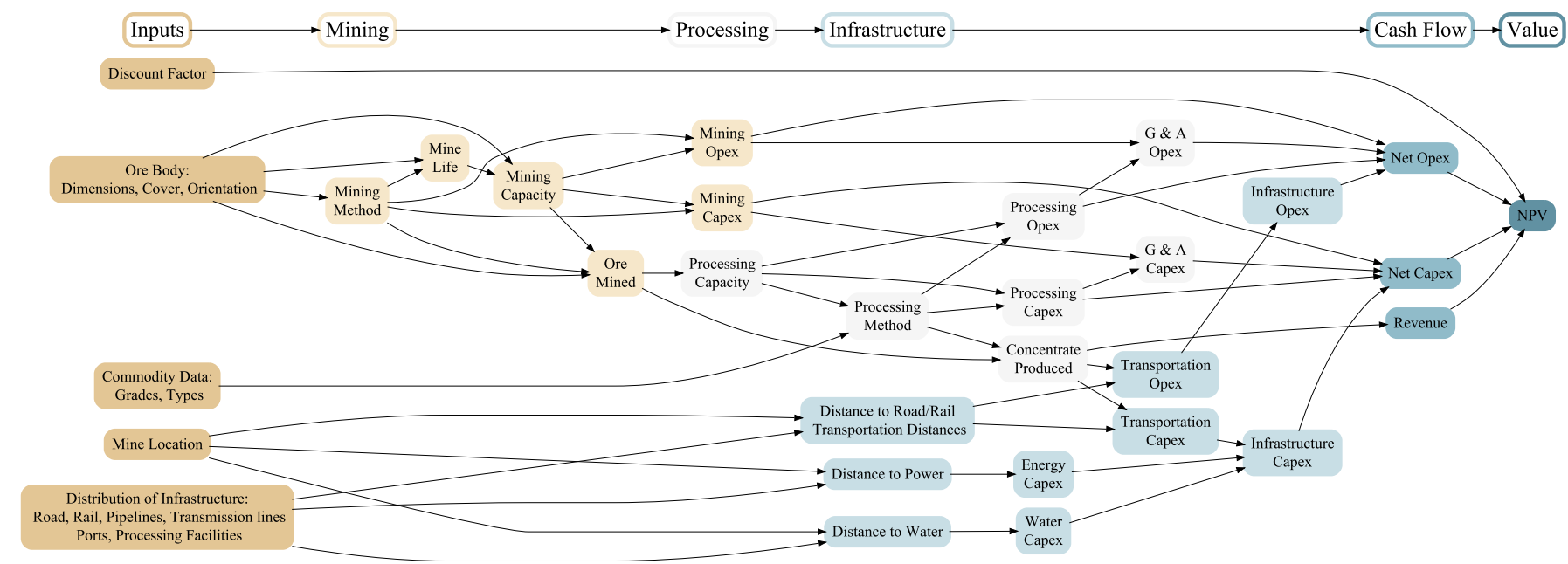

Fig. 2. Flowchart for the model calculation.

\section{Bluecap model}

While Bluecap can be applied to assessments of individual locations, the simulator's main intent is to compare the economic viability of development over large areas rather than on a site-by-site basis. To do so, an idealised mine-valuation is constructed for each point within the region under consideration using the following approach:

- Orebody description: The valuation begins with a description of an ore body (e.g. grade, geometry, depth of cover and location) and additional input parameters governing the mine economics (e.g. commodity prices and company discount factor).

- Mining system: An appropriate mining method for the ore body is then automatically determined based on the geometry and amount of cover. The production rate is estimated using a modified form of Taylor's rule based on the choice of mining method.

- Processing system: The processing method is found based on the type of mineral mined. Economically material secondary minerals are converted into primary mineral equivalents. The processing capacity is estimated from the amount of ore produced from the mine.

- General and Administrative (G\&A) costs: Administrative overhead is determined based on a fixed percentage (typically 14\%) of the mining and processing costs.

- Infrastructure: Power, transportation and water costs are calculated from the location of the mine and its energy and water requirements.

- Cash Flow: Net revenue, and associated royalties and taxes are determined. From this the net cash flow is calculated for each year of the mine's life.

- Economic analysis: Finally the net present value of the mine is obtained from the cash flow and then used to map the relative economic viability of the mining prospect.

The components of each calculation and their dependencies are illustrated in Fig. 2 and described in the sections below. We also describe how the outputs of this model are used to determine how economic constraints (e.g. the break-even ore grade or resource tonnage) are affected as a result of influencing factors (e.g. changing resource depth and distance to infrastructure) across regional areas.

\subsection{Orebody types and mining methods}

Bluecap operates using a simplified description of the orebody geometry. For example, if the approximate dimensions are unknown, then an estimated ore-body volume may be used. This is the approach adopted for all examples given in this paper. However, in some regions specific ore-body geometries are more prevalent for particular commodities. In which case dimensions may be defined in terms of width, length, vertical extent, overburden and dip. For example, komatiitehosted nickel sulphide deposits are typically found in one of two geometries, either as lenses 5-50 m thick, with widths between 50-300 m and extents up to $2 \mathrm{~km}$, or as lenticular zones up to $800 \mathrm{~m}$ thick, 1-3 km wide, with more than $1 \mathrm{~km}$ down-plunge extent (Dowling and Hill, 1998), while in contrast Archaean lode-gold deposits are typically more tubular and smaller with 1-20t contained gold (Groves and Foster, 1991). However, it should be noted that the geomorphology of ore bodies and mineralisation systems can be highly complex, and defined mineral resources and reserves within these can be quite fragmented. If the deposit is highly heterogeneous or discontinuous, the model may underestimate the mining cost. Understanding these complexities requires detailed knowledge of individual mineral deposits, which are not able to be incorporated into a regional assessment. Therefore, the Bluecap model has been designed in a way to significantly simplify the geological description of deposits to enable consistent evaluation across regions, while acknowledging that this simplification results in an added degree of unavoidable uncertainty in final model outputs.

\subsection{Mining system}

Once the ore-body geometry is determined, the mining system can be evaluated. In Bluecap, the mining system calculations involve three distinct stages, namely: i) assessing the type of mining method; ii) calculating the mine life and capacity; and iii) determining the mining costs. The details of each of these are described in the sections below.

\subsubsection{Mining method}

The model distinguishes between open-pit, mixed and underground techniques for developing each ore-body. Underground mines are further classified into Block-Caving; Sublevel-Stoping; Room-and-Pillar; and Cut-and-Fill categories. The class of mining method selected affects the cost and rate of production, as well as the degree of waste and dilution.

In the model, the choice of whether to develop the orebody using an open-pit, mixed, or underground mining method is based on the estimated cost of excavating the ore-body. The model performs separate calculations for all options, and selects the method predicted to generate the greatest Net Present Value (NPV).

For open-pit mines, we first determine the life of the mine and corresponding average rate of production based on Taylor's rule (Taylor, 1977) (see below). It should be noted that Taylor's rule determines the capacity of the processing plant (i.e. the amount of ore processed not the 

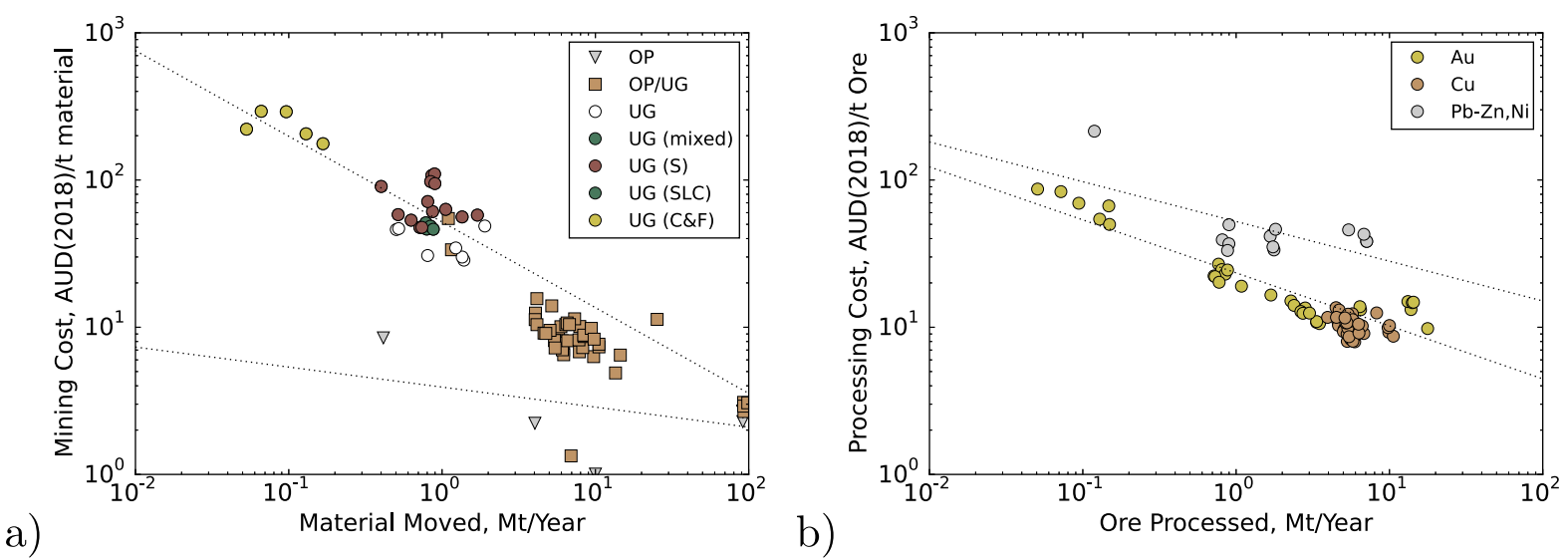

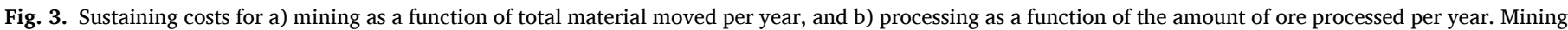

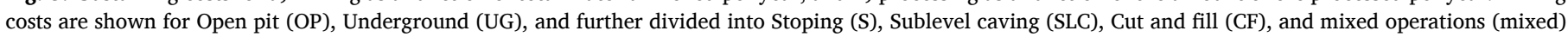

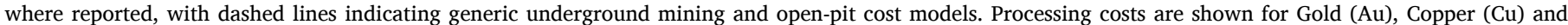

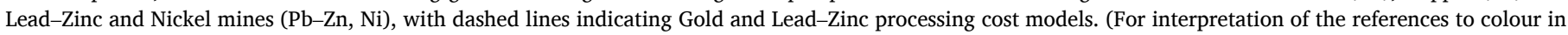
this figure legend, the reader is referred to the Web version of this article.)

amount mined). In the model, we assume that the processing rate will be constant throughout the mine's life (whether open-pit or underground). We also assume that mining will transition from open-pit to underground methods, if economic to do so. The depth of this transition is found by calculating the depth at which the marginal cost per tonne of ore produced using open pit methods equals the cost of per tonne of ore using underground techniques.

Complicating the calculation is the fact that the mining cost depends on the mining system capacity, which is found from the total amount of material (ore and waste) mined. We assume that the mining capacity is sufficient to produce a quantity of ore that is on average equal to the processing plant's capacity over the duration of the open-pit mining operation. As the switching depth is itself a function of the capacity (and hence implicitly related to the mining cost), this depth is evaluated numerically using an iterative approach. To simplify the calculation, the mine cost model does not account for additional capital costs incurred when transferring from an open-pit to an underground operation. Potential capital costs associated with these transitions include detailed mine planning and design, construction and installation of service infrastructure (e.g. ventilation systems and shafts, underground crushers), and mining of access and development shafts. These can be considered relatively minor on a life-of-mine basis. As it is common in the Australian mining industry for mining and production drilling fleets to be owned by mining contractors rather than be purchased directly by the controlling company of the mine, we assume that these equipment costs are factored into our underground mining cost estimates.

For underground mines, the choice of which underground mining method to use is based on the ore-body geometry. The model currently recognizes four broad categories of underground mining methods: block-caving; sublevel-stoping; room-and-pillar; and cut-and-fill. Blockcaving mining methods are appropriate for massive orebodies with near vertical orientation with a large cross-sectional area. Camm (1991) recommends block caving for wide-vein deposits, greater than $100 \mathrm{ft}(\sim$ $30 \mathrm{~m}$ ) with a steep dip. The meaning of "steep" is subjective, but is defined as greater than $50^{\circ}$ by Carter (2011) who recommends block caving for ore bodies more than $30 \mathrm{~m}$ in width. Conversely, room-and-pillar methods are employed in near-horizontal orebodies with a flat dip. Camm (1991) defines "near-horizontal" as less than $30^{\circ}$, while Carter (2011) places the cutoff at $20^{\circ}$. For the purpose of the model, a dip of $25^{\circ}$ is used as the default cut-off. Cut-and-fill mining methods are appropriate for very narrow ore-body geometries. While they are more expensive per tonne than other methods both in terms of capital and operating costs, they offer higher selectivity. This makes cut-and-fill methods attractive for narrow vein/low capacity mines.
Again what is "narrow" is subjective, but is defined as less than $10 \mathrm{~m}$ according to Carter (2011). The final underground mining category is sublevel-stoping. In practice sublevel-stoping methods are applicable to a range of orebody widths, with a range of orientations. This is the mining method assumed for all remaining orebody geometries.

Sustaining costs for mining operations are found from data extracted from end of financial year reports sourced from publicly listed Australian mining operations (Fig. 3a). A power-law relationship is determined for open-cut and underground mines based on an estimate of cost per ton of material (waste and ore) produced versus mine capacity (again in terms of total material mined - waste and ore).

\subsubsection{Mine life and production}

The rate of mine production is estimated using modified versions of Taylor's rule (Taylor, 1977), a power-law relationship that expresses the production rate (in $\mathrm{mt} / \mathrm{day}$ ) to the total tonnage of ore to be mined:

$P=a T^{b}$,

where $T$ is the total tonnage of ore to be mined in tonnes, $P$ is the production rate in tonnes per day, and $a$ and $b$ are empirically determined constants. Under Taylor's original formulation $a=0.0143$ and $b=$ 0.75 . However, Taylor's rule is an empirical equation which was originally based on data from mines with mixed types of operations dating back several decades. Since its publication several modifications to Taylor's original formulation have been proposed. Here, we employ the extensions to Taylor's rule published by Long (2009) for generic open-pit, block caving and underground mines. For generic open-pit and block-caving operations, Long (2009) gives the Taylor's rule parameters as $a=0.123$ and $b=0.649$, whereas for underground operations (apart from block-caving), the parameters are $a=0.297$ and $b=0.562$. These default relationships may be adjusted by the user to suit their own development strategies.

Once the production rate is established, the operating mine life, $L$, is estimated from the mine production, $P$, and operating days per year, $d p y$, (assumed to be 350):

$L=T /(P \cdot d p y)$

where $L$ is years of operation.

\subsubsection{Ore and waste}

For underground mines, the volume excavated in developing the access ramp is assumed to be waste. Underground ore bodies are assumed to be accessed by a decline of fixed cross-sectional area. By 


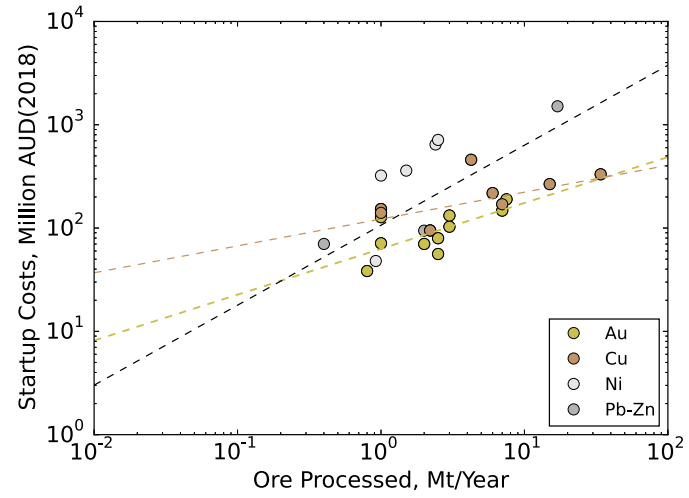

Fig. 4. Startup costs as a function of plant capacity for Gold (Au), Copper (Cu) and Lead-Zinc $(\mathrm{Pb}-\mathrm{Zn})$ and Nickel mines $(\mathrm{Ni})$, with dashed lines indicating Gold, Copper and Lead-Zinc startup cost models. (For interpretation of the references to colour in this figure legend, the reader is referred to the Web version of this article.)

default, the Bluecap model assumes a constant ramp cross-section of $5 \mathrm{~m} \times 5 \mathrm{~m}$ with a grade (slope) of $10 \%$. The volume of material excavated is given by

$V_{\text {ramp }}=A_{\text {ramp }} \Delta d / \sin \left(\theta_{\text {ramp }}\right)$,

where $A_{\text {ramp }}$ is the cross-sectional area, $\Delta d$ is the change in depth of the ramp and $\sin \left(\theta_{\text {ramp }}\right)$ is the grade. For sublevel-stoping, room-and-pillar, and cut-and-fill mining methods production is assumed to start once the ramp has been built to the top of the ore-body. For block-cave mines production commences after the ramp has been built to the base of the ore body. In taxation calculations, ramp-development costs are assumed to be capitalized and depreciated over the remaining life of the mine.

For open pit mines the distribution of waste and ore is determined from the ore-body geometry. As the ore body is assumed to have a rectilinear geometry, the ore excavated is equal to the increment in depth $\Delta d$ multiplied by the horizontal width $w$ and length $l$ of the deposit.

$M_{\text {ore }}=w \cdot l \cdot \Delta d$

The ratio of ore to waste in open-pit mines depends on the slope of the mine pit, $\alpha$, here assumed to be equal to $40^{\circ}$. If the mine slope is less than the ore-body dip, $\beta$, the previous void volume is contained within the volume of the new excavation cone as the pit descends. Under these circumstances the total volume removed is:

$$
\begin{gathered}
M_{\text {total }}=w \cdot l \cdot \Delta d+\frac{1}{2}(2 w+2 l) \cot (\alpha)\left[(d+\Delta d)^{2}-d^{2}\right] \\
+\frac{\pi}{3} \cot ^{2}(\alpha)\left[(d+\Delta d)^{3}-d^{3}\right] .
\end{gathered}
$$

When the mine slope is greater than the ore-body dip only part of the previous void volume is contained within the new volume excavated. In this case, the volume removed is approximated as:

$$
\begin{gathered}
M_{\text {total }}=w \cdot l \cdot(d+\Delta d)-[w-(\cot (\beta)-\cot (\alpha)) \Delta d] \cdot l \cdot d \\
-\frac{1}{2}[l+2 w-2(\cot (\beta)-\cot (\alpha)) \Delta d] \cot (\alpha) d^{2} \\
+\frac{1}{2}(l+2 w) \cot (\alpha)(d+\Delta d)^{2}+\frac{\pi}{6} \cot ^{2}(\alpha)\left[(d+\Delta d)^{3}-d^{3}\right]
\end{gathered}
$$

\subsection{Processing system}

The processing capacity determines the average amount of ore treated over the life of the mine. Processing and milling costs are based on the type of commodity produced. Startup and ongoing cost models
Table 1

Estimates of refining take and metal concentrations in concentrate used in the model for select commodity types. Based on values provided in Burt et al. (2012); Perth Mint (2019).

\begin{tabular}{lll}
\hline Commodity & Concentrate content & Refining take \\
\hline $\mathrm{Au}$ & $75 \%$ & $1 \%$ \\
$\mathrm{Cu}$ & $25 \%$ & $10 \%$ \\
$\mathrm{Ni}$ & $30 \%$ & $30 \%$ \\
$\mathrm{~Pb}-\mathrm{Zn}$ & $50 \%$ & $17 \%$ \\
\hline
\end{tabular}

are found for $\mathrm{Au}, \mathrm{Cu}-\mathrm{Au}, \mathrm{Ni}-\mathrm{Cu}$ and $\mathrm{Pb}-\mathrm{Zn}-\mathrm{Ag}$ deposits based on reported processing-plant capital costs given in feasibility studies (Fig. 4) and sustaining costs reported in financial documents (Fig. 3b).

Recovery rates vary depending on the type of processing method. For example, Camm (1991) gives a range of recovery rates from $93 \%$ for gravity milling methods to a low of $70 \%$ for heap leaching. There are examples internationally of recoveries much lower than this (e.g. 50\%), for instance from projects that dump leach marginal copper oxide ores. However, the long-term, global recovery rate of copper to concentrates via flotation processes has been in excess of $85 \%$ since the 1920 s (Gordon, 2002). Therefore, we assume a default $90 \%$ recovery (regarded as typical for flotation methods) for all processing methods. The recovery rate can be adjusted by the user as part of the input file.

The volume of concentrate produced and smelter return are based on estimates of concentrate concentration and refining take given by the AusIMM cost-estimation handbook (Burt et al., 2012). However, it should be noted that there may be significant variations in these values depending on commodity price and ore concentration. The values used in the examples presented in this paper are given in Table 1.

The amount of concentrate produced is determined from the metal fraction in the unprocessed ore multiplied by processing losses, divided by the concentrate mass fraction:

$M_{\text {conc }}=\left(1-l_{\text {proc }}\right) \frac{\varphi_{\text {ore }}}{\varphi_{\text {conc }}} M_{\text {ore }}$,

where $M_{\text {conc }}$ is the mass of concentrate, $M_{\text {ore }}$ is the mass of ore, $\varphi_{\text {ore }}$ is the mass fraction of metal in the ore, $\varphi_{\text {conc }}$ is the mass fraction of the metal in the concentrate and $l_{\text {proc }}$ is the processing loss fraction. The amount produced each year multiplied by the distance to the nearest port or processing facility is used to calculate the transportation costs described in greater detail in Section 2.5.3.

\subsection{General and Administrative Costs}

General and administrative (G\&A) costs are based on a fixed proportion of overall mining and processing costs. The AusIMM handbook (Burt et al., 2012) estimates that G\&A costs vary from 8-10\% of overall costs for large Australian mines near residential neighbourhoods to $15-20 \%$ of overall mine costs in remote locations. Curry et al. (2014) examined operating cost breakdown using publicly available data from operating mines and feasibility studies in 65 different mining operations. In the Curry et al. (2014) dataset, G\&A costs made up $13.3 \%$ of overall costs on average with a median of $11.0 \%$. The six Australian mines that they considered had a similar distribution of costs with a mean of $13.9 \%$ administrative costs and a median of $12.6 \%$. Our own analysis of financial reports of Australian mines returned a similar result with G\&A costs constituting $14.6 \%$ of the total of mining, processing and G\&A costs in mining operations. For the examples given in this paper, we assume that G\&A costs are $14 \%$ of overall costs.

\subsection{Infrastructure}

Following the recommendations outlined by the AUSIMM costestimation handbook (Burt et al., 2012), we consider three different classes of infrastructure costs: Power, Water and Transportation. Power 
Table 2

Estimated capital costs for powerlines

\begin{tabular}{llll}
\hline Voltage $(\mathrm{kV})$ & Cost $(\$ 1000$ AUD $/ \mathrm{km})$ & Year & Source \\
\hline 11 & $50-100$ & 2010 & Burt et al. (2012) \\
33 & $200-400$ & 2010 & Burt et al. (2012) \\
132 & $400-700$ & 2014 & Brinsmead et al. (2014) \\
220 & $750-1100$ & 2014 & Brinsmead et al. (2014) \\
\hline
\end{tabular}

Table 3

Average raw water use depending upon processing route, derived from Northey et al. (2018).

\begin{tabular}{lll}
\hline Process & Raw Water Inputs & No. Mines \\
\hline & $\mathrm{kL} / \mathrm{t}$ ore processed & \\
Cyanidation (Tank) & 1.27 & 19 \\
Floatation & 2.35 & 18 \\
Heap Leach & 0.24 & 8 \\
\hline
\end{tabular}

and water operating costs are components of general operating costs for both the mining and processing system. Accordingly, these costs are not included in the cost model to avoid double counting. However, they are separately accounted for when determining the startup costs for the mine. Transportation costs are included in both startup and sustaining cost calculations. These include both the cost of establishing the connection to the existing rail or road infrastructure, as well as the costs to transport processed concentrate to the refinery. The details of these calculations are outlined below.

\subsubsection{Power}

According to the AusIMM cost-estimation handbook (Burt et al., 2012) powerline voltages of $11 \mathrm{kV}$ are used for most mines, with larger voltages reserved for longer distances. The $11 \mathrm{kV}$ voltage lines recorded in the Open Street Map Database (OpenStreetMap contributors, 2018) are less than $1 \mathrm{~km}$ in length. The next highest voltage, $33 \mathrm{kV}$ lines are slightly more common with the longest being approximately $150 \mathrm{~km}$ in length, though the majority listed in the database are less than $100 \mathrm{~km}$. Examples of $220 \mathrm{kV}$ lines are recorded up to $275 \mathrm{~km}$ in length, however $132.5 \mathrm{kV}$ lines are more prevalent up to $190 \mathrm{~km}$. In the Bluecap model, the required voltage is set to $11 \mathrm{kV}$ if the distance to power is less than or equal to $1 \mathrm{~km}, 33 \mathrm{kV}$ if it is less than or equal to $150 \mathrm{~km}, 132.5 \mathrm{kV}$ for distances up to $190 \mathrm{~km}$, and $220 \mathrm{kV}$ otherwise. The capital costs associated with each voltage line are summarized in Table 2.

\subsubsection{Water}

Water supply requirements of mining operations vary due to local climate, ore processing requirements and site specific water management strategies. The majority of water used at base and precious metal mines is used for ore processing. Therefore, the ore processing method, in combination with ore throughput rates, can be used to constrain estimates of the required rates of raw water supply to a mining operation. Average raw water use of mines depending upon the three ore processing routes considered are shown in Table 3.

Assuming that all raw water is sourced externally to the site from groundwater bores or surface water systems, then the required internal diameter of a water supply pipeline to the site can be determined by combining the values in Table 3 with average ore throughput rates and pipeline velocity.

$d=\sqrt{\frac{4}{\pi} \frac{O q}{365 \cdot 24 \cdot 3600 \cdot v}}$

where $d$ is internal diameter (meters), $\mathrm{q}$ is raw water inputs $\left(\mathrm{m}^{3}\right.$ per tonne ore), $\mathrm{O}$ is the annual ore throughput (tonnes per year) and $\mathrm{v}$ is the average velocity. A velocity of $2 \mathrm{~m} / \mathrm{s}$ is typical for water supply pipelines. The internal diameter of the pipeline and the distance to the nearest water source can then be used to estimate the costs of water
Table 4

Transportation costs in 2010 AUD (Burt et al., 2012).

\begin{tabular}{|c|c|c|c|}
\hline \multirow[t]{2}{*}{ System } & Capital costs & Fleet Costs & Operating Costs \\
\hline & 1000AUD/km & 1000AUD/(km·Mt/a) & cents $/ \mathrm{t} / \mathrm{km}$ \\
\hline Road & $500-3000$ & 40 & $5-12$ \\
\hline Rail & $2000-7000$ & 100 & $1-1.25$ \\
\hline
\end{tabular}

pipeline infrastructure.

Pipeline and pumping costs per kilometer are estimated from a linear fit of cost estimates for 54 pipelines (Miriam Vale Shire Council, 2007; Tonkin Science Engineering, 2011; Wise and Raft, 2013; Gao et al., 2016).

$C_{\text {pipeline }}=2662900 \mathrm{~d}-125528$,

where $d$ is the pipe diameter in $m$ and $C_{\text {pipeline }}$ is the pipeline cost per kilometer in Australian (2018) dollars. The minimum cost per kilometer is fixed at $\$ 250,000 / \mathrm{km}$ based on data in Burt et al. (2012).

\subsubsection{Transportation}

Under the AusIMM cost estimation model, transportation costs are divided into three components: the cost of connecting to the nearest transportation route (i.e. building the required rail or road); capital costs associated with the fleet; and ongoing costs required for transporting the concentrate to market (Burt et al., 2012, and Table 4). In Bluecap, we calculate the cost of both road and rail transportation from the mine to the nearest refinery or major port, and select which mode of transportation gives the greatest net present value for the mine.

Port locations were based on the dataset provided by the Australian Customs and Border Protection Service (2015). Not all ports in the dataset have facilities to export concentrate and minerals. Accordingly, appropriate export ports were identified by examining trade statistics published by Ports Australia (Ports Australia, 2013, 2015) - including only those that had exported dry bulk goods between 2013-2015. Data released by the Queensland government on exports from major ports was used to include ports that had exported iron ore and non-ferrous minerals in the last 10 years (Queensland Government Statistician's Office, 2018). Mineral processing facilities are based on data given in the Mineral Processing Plants dataset produced by the Australian Mines Atlas (Australian Atlas of Mineral Resources, Mines and Processing Centers, 2014).

Distances to road and rail are calculated based on data obtained from Open Street-Maps database (OpenStreetMap contributors, 2018). The Euclidean (straight-line) distance to the nearest road/rail line multiplied by the expected tortuosity is used to determine the transportation cost calculation. The average rail tortuosity (i.e. ratio of end-to-end distance to actual distance) is $\sim 1.2$, but this is affected by short lines, which have significantly higher tortuosity on average. Rail tortuosity is better approximated as 1.1 for railways over $5 \mathrm{~km}$ long. The tortuosity decreases as length increases but remains relatively constant for lines between $5 \mathrm{~km}$ and $150 \mathrm{~km}$ in length. Likewise Australian road tortuosities in the Open Street-Maps database are similarly distributed with an average of 1.1. It should be noted that tortuosities are approximately log-normally distributed, thus a typical road or rail line will have slightly lower tortuosity than the average value, however occasionally the tortuosity will be significantly greater.

\subsection{Economic model}

Once the mining and processing methods have been established, the revenue, and the capital and operating costs for the mine can be determined. Mine revenue is estimated based on a fixed percentage of the market value of mineral content of the concentrate produced. The percentage depends on the type of metal and reflects fees and losses incurred during the refining process as detailed in Section 2.3. The cost 
Table 5

Examples of gold royalty rates for Australian states and territories, based on rates described in Government of Western Australia (2015) and Geoscience Australia (2017).

\begin{tabular}{ll}
\hline State & Royalty \\
\hline $\begin{array}{c}\text { New South } \\
\text { Wales }\end{array}$ & $\begin{array}{l}4.0 \% \text { of the ex-mine value (i.e. market value less allowable } \\
\text { deductions). }\end{array}$ \\
Victoria & Nil. \\
Queensland & $\begin{array}{l}\text { Variable rate between } 2.5 \% \text { and } 5.0 \% \text { depending on commodity } \\
\text { price. }\end{array}$ \\
South Australia & $\begin{array}{l}3.5 \% \text { of net market value in metal form. } \\
\text { Tasmania }\end{array}$ \\
$\begin{array}{l}1.9 \% \text { on net sales plus a profit royalty (equal to } 0.4 \mathrm{profit}^{2} / \mathrm{net} \\
\text { sales). The maximum royalty is capped at } 5.35 \% \text { of net sales. }\end{array}$ \\
$\begin{array}{l}\text { Northern } \\
\text { Territory }\end{array}$ & $\begin{array}{l}\text { expenses, and exploration expenses. } \\
\text { Western } \\
\text { Australia }\end{array}$ \\
\hline
\end{tabular}

calculation is broken down into the following major components: Mining Costs; Processing Costs; General and Administrative Costs; Infrastructure Costs; and Royalties and taxes. The cash flow for each year of the mine's operation is then used to estimate the economic viability for each location.

All historic costs have been indexed using the Australian Bureau of Statistics' Producer Price Index for Inputs to the Coal Industry (Australian Bureau of Statistics, 2018), which we adopt as a proxy for rates of inflation in the broader Australian mining sector. Where historic cost data was reported in foreign currencies (usually U.S. dollars), conversions to Australian dollars were performed using company reported achieved exchange rates when available. When these were not available, currency conversions were performed based upon the mean of monthly exchange rates, reported by the Reserve Bank of Australia for that calendar year (Reserve Bank of Australia, 2018). Conversion to Australian dollars was always performed prior to indexing.

Real startup and sustaining costs are calculated over the life of the mine. These are then apportioned into capital and operating expenses. After which all expenses and revenue are converted into nominal prices assuming a constant inflation rate (set to $2 \%$ by default). Nominal Capex is used for depreciation calculations and depreciated expenses are not inflated .

Royalties are calculated on a state-by-state basis and are contingent on the type of metal produced (see State of Queensland, 2013; Government of Western Australia, 2015; State of Tasmania, 2016; Geoscience Australia, 2017a,b). Examples of the royalty calculations for gold are given in Table 5. While most royalties are profit or value based, in New South Wales, mineral royalties are based on ex-mine value. In the Bluecap model, this is estimated based on the value of the contained minerals less transportation and processing expenses, depreciated capital expenses from processing and transportation, and one third of administrative expenses (NSW Resources and Energy, 2014).

Income tax is assumed to be levied at $30 \%$ of the mine profits, i.e. revenue minus operating expenses and depreciated capital expenses. It is assumed that tax losses in a given year are carried forward and counted against future revenue. Depreciation on capital expenses is assumed linear over the remaining life of the mine. Capitalized expenses are assumed to be $20 \%$ of all-in sustaining costs based on analysis of financial reports.

The economic viability of a particular location is determined from the Net Present Value (NPV) of a mined deposit at that position, i.e. the sum of discounted future cash flows over the life of the mine:

$N P V=\sum_{i}^{N_{\text {years }}} \frac{N C F_{i}}{\left(1+r_{d}\right)^{i}}$

where $N_{\text {years }}$ is the number of years of operation, $N C F_{i}$ is the net cash flow for year $i$, and $r_{d}$ is the company discount rate (assumed to be $5 \%$ in this paper).

Feasibility studies often include estimates of the proportion of operating and capital costs spent on labour. In the model, direct employment levels are estimated based on a linear fit of employment estimates versus capital investment given in the Resources and Major Energy Projects list produced by the Department of Industry and Science, Office of the Chief Economist (2015). Indirect employment benefits arising from mining operations are not determined, but have been estimated elsewhere at $135 \%$ of direct employment (Deloitte Access Economics, 2017). a)

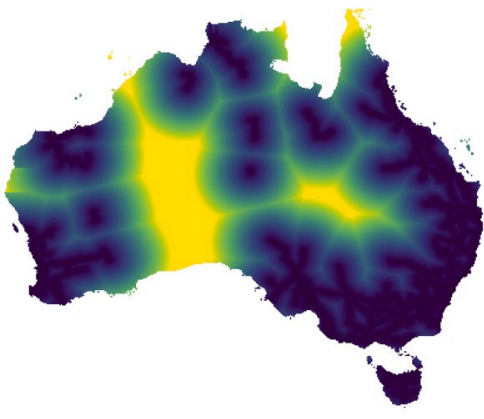

b)
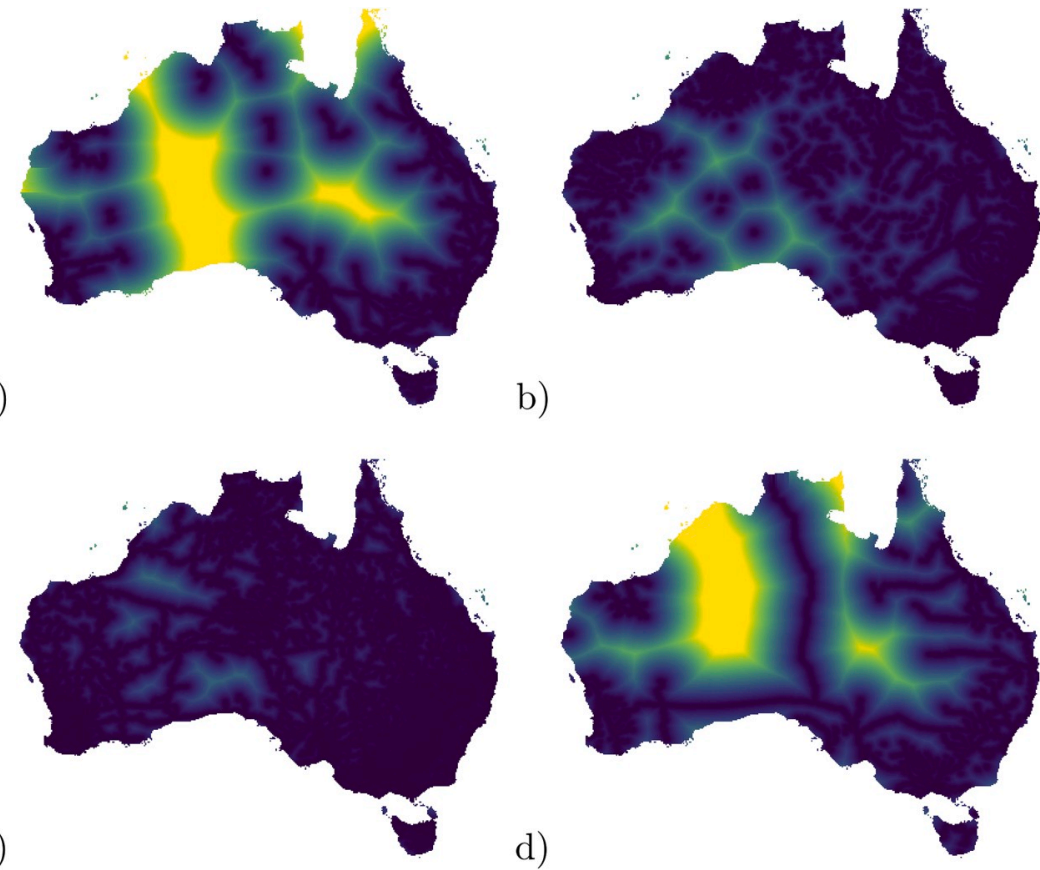
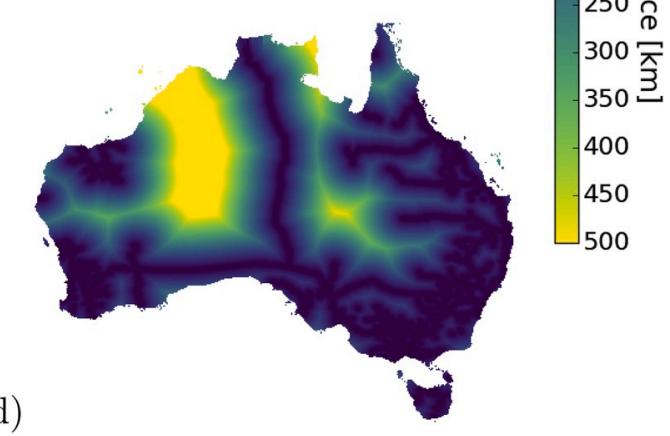

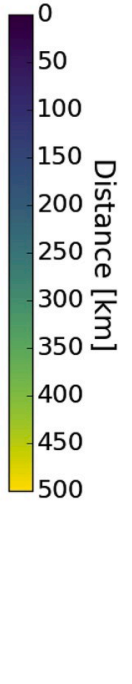

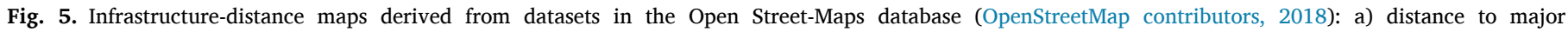
power-transmission lines; b) distance to the nearest water source; c) distance to road transportation; and d) distance to rail. 
a)
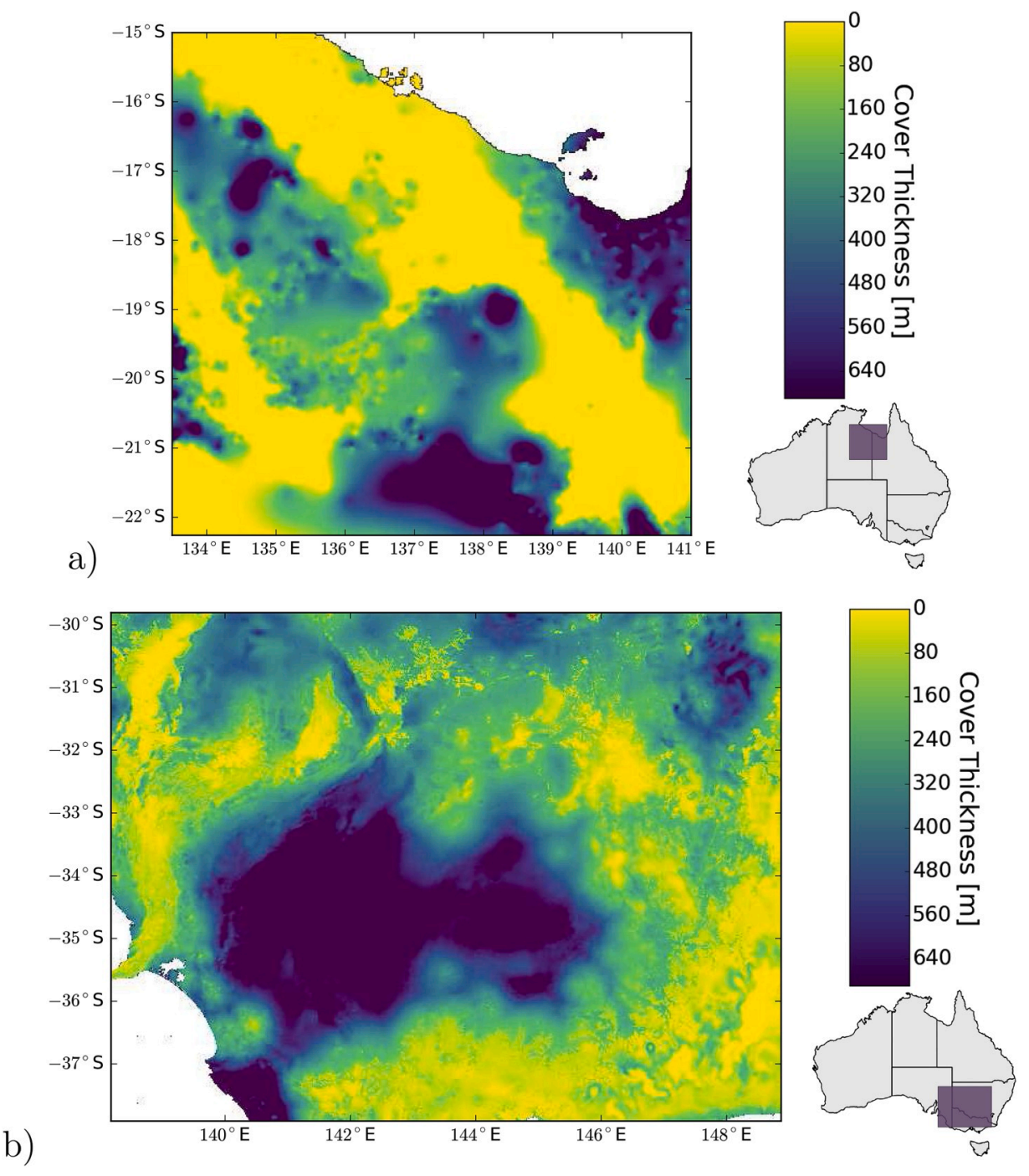

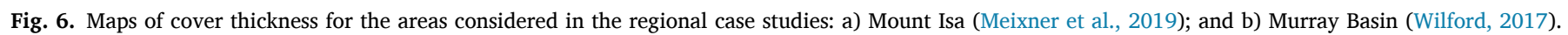

\section{Regional calculations}

Regional calculations are conducted by separating the model components into those that depend on the depth of cover, from those that depend on distances and locations. For example, in the model, mining costs depend on the depth of cover, but not the location. Accordingly for regional calculations, the single-site model is used to generate a custom lookup table for the mining costs that is a function of the cover depth. Similarly, the processing costs depend on the amount (and type) of ore mined. Thus, these are also precalculated and included in the lookup table for the mine costs, along with the contribution from G\&A expenses. At the same time, lookup tables are also generated for the transportation capacity and amount of concentrate produced over the life of the mine which are needed to determine transportation costs. The amount of concentrate is reduced by the company discount rate to account for the time value of money.

The generated lookup functions are then applied to the cover maps to produce regional maps of the values generated by the mining system (Fig. 5). The regional value maps are then combined with the regional maps of the distance to power and water infrastructure weighted by their individual costs (reduced by 30\% to account for the effect of tax), to assess the cost of these services. Transportation startup and ongoing costs are similarly estimated using the maps for distance to infrastructure maps for road and rail, those for distance to the nearest processing port or center, in combination with the cover map and the lookup tables for the amount of concentrate produced and the required fleet capacity.

\section{Case studies}

In this section, we present results of detailed regional case studies examining deposits in the Mount Isa region and the Murray Basin. The two regions were selected due to their historic connection to the mining industry as well as the ready availability of high resolution maps of the depth of cover for both areas. Cover depths for the Mount Isa region are based on the Tennant Creek to Mt Isa cover model (Meixner et al., 2019) extended to -22 S applying the same method and input datasets (Fig. 6a), while over the Murray Basin, the Murray Basin Cenozoic thickness cover map (Wilford, 2017) was used (Fig. 6b).

In the Mount Isa region, we consider model predictions for locations that include 28 copper and 17 lead-zinc mines and deposits. Input data for each point (location, grades and sizes) are based on information obtained from the Australian Atlas of Mineral Resources, Mines and Processing Centers (2014), augmented by more recent grade and deposit estimates given in company reports. The dataset includes 11 recently-operating copper and 9 recently-operating lead-zinc mines. The remaining deposits are a combination of historical mines no-longer in operation and undeveloped deposits.

As shown in Fig. 7a, the model correctly categorizes all but one of the 


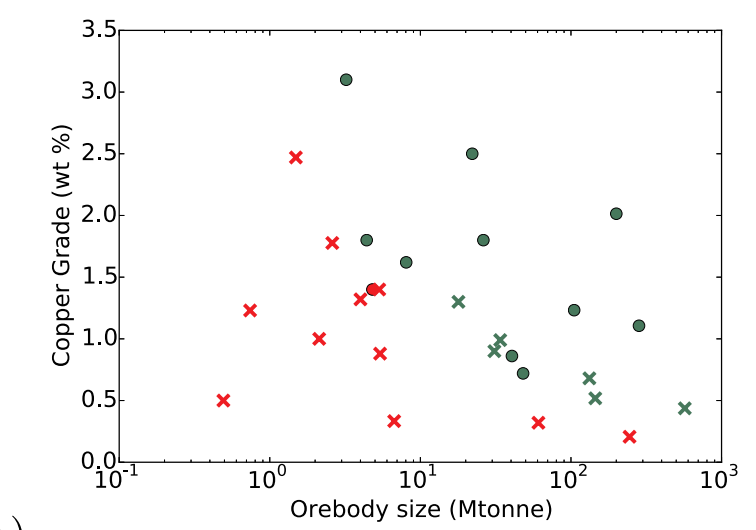

a)

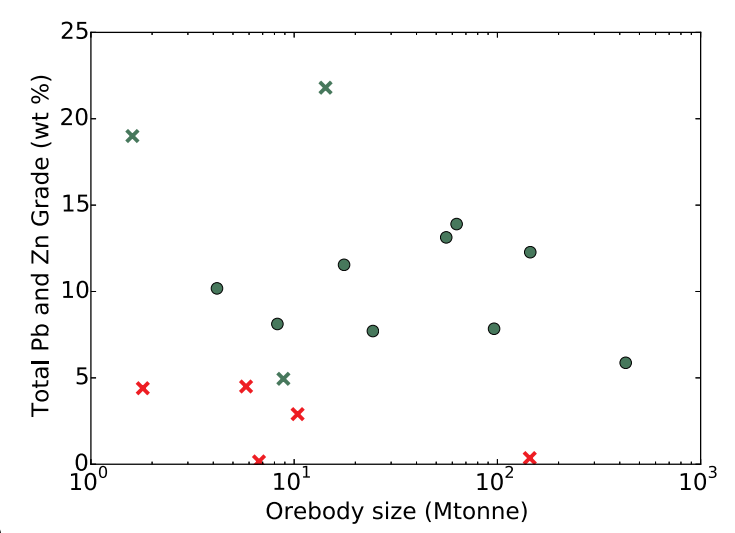

b)

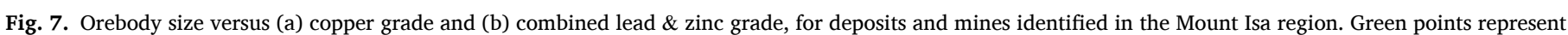

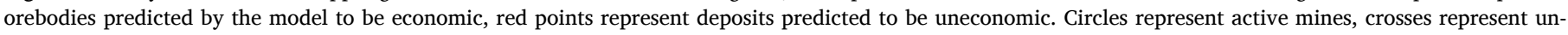

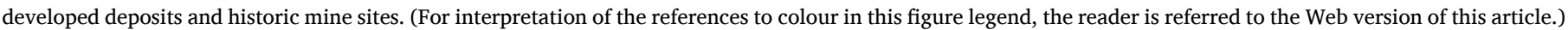

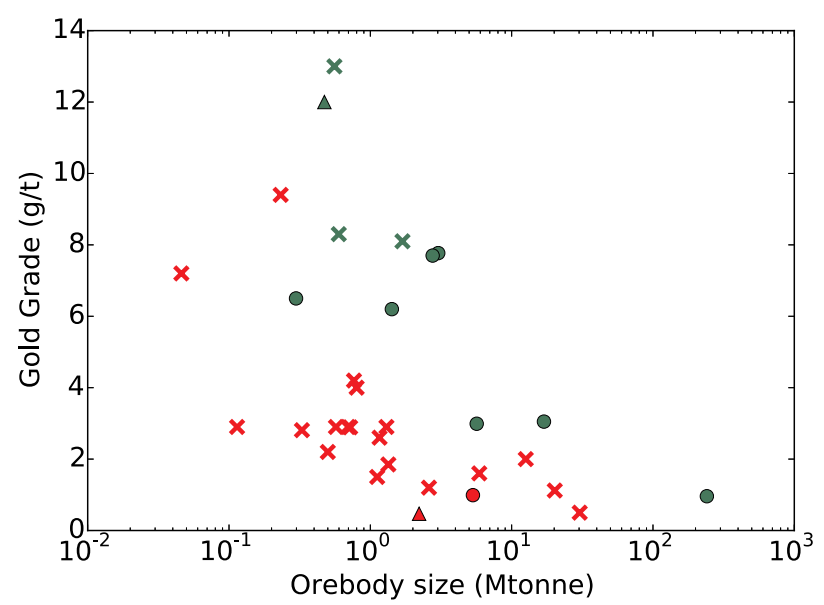

Fig. 8. Orebody size versus gold grade for deposits and mines in the Murray Basin. Green points represent orebodies predicted to be economic by the model, while red points represent uneconomic predictions. Circles show recently active mines; crosses undeveloped deposits and historic mine-sites; and triangles indicate mines in care-and-maintenance. (For interpretation of the references to colour in this figure legend, the reader is referred to the Web version of this article.)

recently-operating copper mines in the Mount Isa region as economic. Of the six non-operating deposits classified as economic by the model, three are historic mines no-longer in operation and one has recently been considered for development (Young Australian, 2018). The story is similar for the lead-zinc deposits (Fig. 7b). All nine recently-operating mines were classified as economic by the model, and all but three of the undeveloped resources were classed as uneconomic. It should be noted that although Fig. $7 \mathrm{~b}$ shows the ore body size versus the combined lead and zinc grades for simplicity, the simulations were conducted with separate grades and prices for each commodity.

For the Murray Basin, 29 gold mines and deposits were identified from the Australian Mines Atlas. The grades and ore-body sizes are based on aggregated sub-deposit values and reserve/resource estimates. The results of the Blue-cap analysis are summarized in Fig. 8. Again the model distinguishes active mines from inactive deposits in the majority of cases. All but one of the active mines were identified as economic by the model, and similarly all but three of the inactive deposits were classified as uneconomic. Two of these three economic deposits are historic mine-sites: the Walhalla gold mine in Victoria; and the Bird-inthe-hand mine in South Australia. The latter is currently being studied to see if it might be re-opened. Of the two mines listed as being in care-andmaintenance in the database, one was classed as economic and the other was uneconomic. The boundary between the economic and uneconomic mines is less well-defined when plotted as a function of the ore-body grade and size (Fig. 8), compared to the previous two examples (Fig. 7). This appears to result from the fact that gold deposits around the Murray-Basin are typically smaller in size and hence more sensitive to variations in cover depth, state royalties and the location of surface infrastructure, than the larger copper and lead-zinc mines in the Mount Isa region.

The increased sensitivity to surface infrastructure in smaller deposits is highlighted in Fig. 9, which shows the results of regional calculations over the Murray Basin. The figure compares the variation in economic viability of a marginal gold deposit with that of a large-scale copper deposit (equivalent to Mount Isa) for the area shown in Fig. 6b. The figure illustrates that economic viability is more heavily influenced by the location of surface infrastructure (proximity to transportation and power in particular) and differences in state royalties in the case of the smaller deposit. In contrast, for larger deposits, knowledge of the coverthickness is typically more important than the distribution of existing infrastructure. The results also suggest that low-grade deposits may be economic regardless of location if they are sufficiently large.

Accurate estimation of mining project feasibility and the development of costs models is inherently difficult. Historically, there have been significant deviations between predicted and actual capital expenditures for major projects in Australia and elsewhere (e.g. Ravensthorpe, Boddington, Prominent Hill), prompting calls for advances in cost modelling (Nourali and Osanloo, 2019). Individual cost and revenue drivers, such as gold ore grades, have previously been shown to be particularly influential over the economics of individual mining projects (e.g. Ulrich et al., 2019). The validation of Bluecap model's ability to distinguish a reasonable break-even cost frontier between potentially economic and uneconomic mineral resources is encouraging given the inherent complexity in the cost estimation processes. Moreover, the Bluecap model provides an avenue to explore how basic changes in deposit characteristics, cost drivers, economic relationships and infrastructure availability may manifest into changes in the economic viability of exploration and mine development in different parts of the Australian continent. These developments may also be considered in terms of other economic outcomes, such as tax revenue and employment generated ( $e$. g. Fig. 10). This approach provides an evidence base for land management policy decisions and in the future could be extended to optimise placement of infrastructure to unlock mineral wealth (when combined 
a)

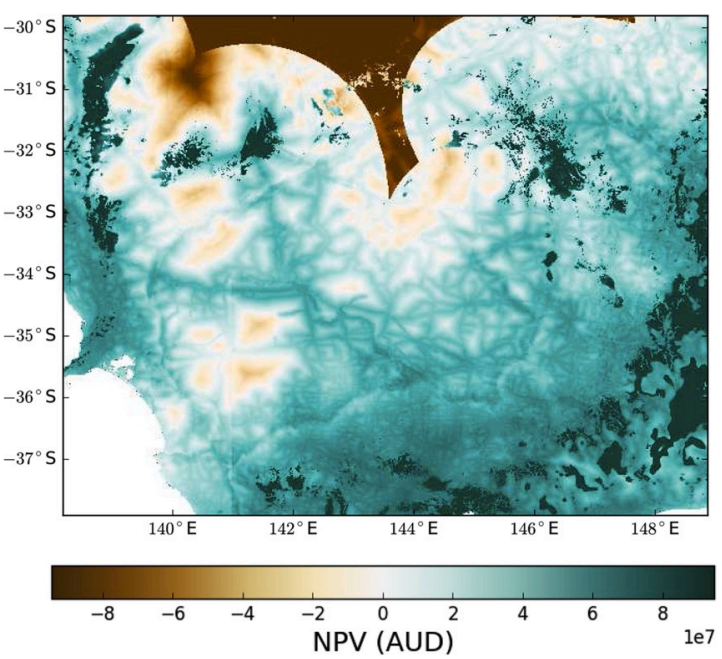

b)

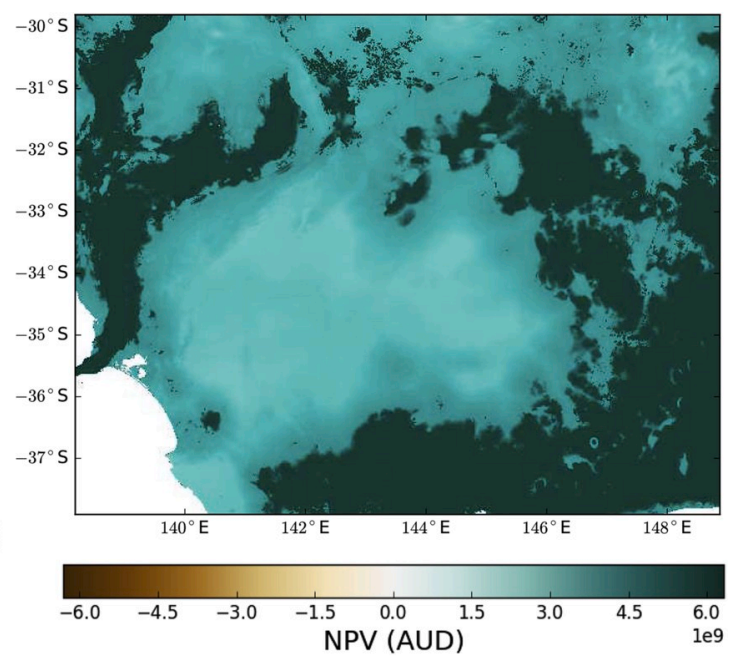

Fig. 9. Spatial variation in NPV for hypothetical a) small high-grade gold deposits ( 8 tonne contained gold at a grade of $6 \mathrm{~g} / \mathrm{t}$ ) and b) massive copper deposits ( 8 Mtonne contained copper at a grade of $0.7 \%$ ) over the Murray Basin. (For interpretation of the references to colour in this figure legend, the reader is referred to the Web version of this article.)

a)

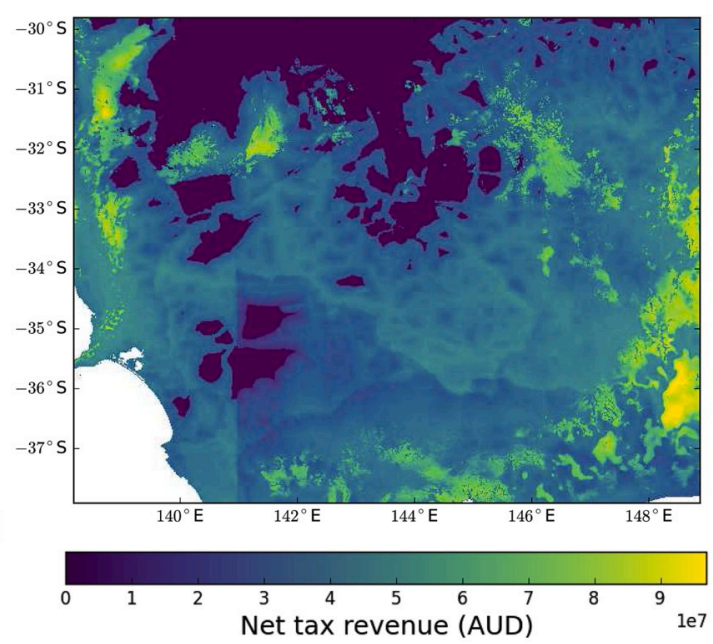

b)

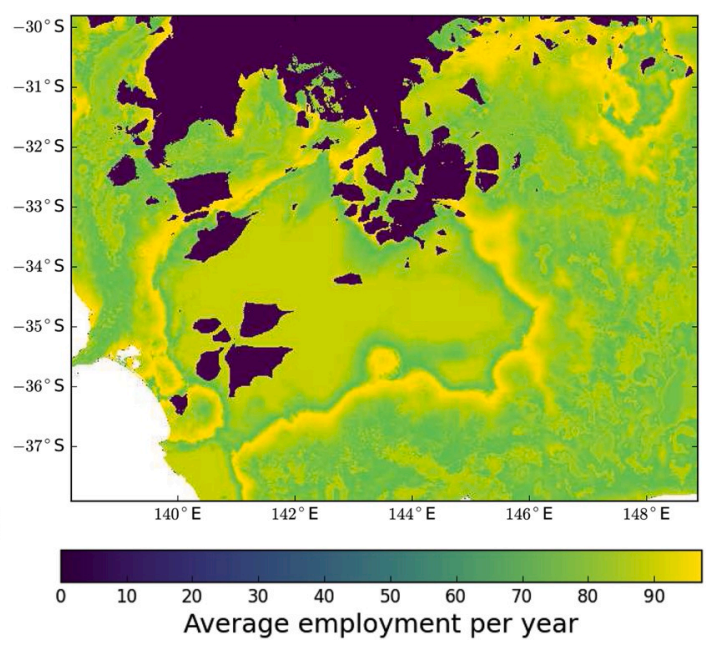

Fig. 10. Estimates of a) net tax revenue and b) average yearly employment from a hypothetical small high-grade gold deposit ( 8 tonne contained gold at a grade of 6 $\mathrm{g} / \mathrm{t}$ ) within the Murray Basin region. (For interpretation of the references to colour in this figure legend, the reader is referred to the Web version of this article.)

with mineral potential assessments) while taking other factors into consideration (e.g. farming etc.).

\section{Conclusion}

The Bluecap simulator provides a simple model for mapping economic viability of mining development in regions across Australia. The model combines an assessment of the mineral potential based on the depth of cover with an evaluation of key economic drivers affecting mining operations. In so doing, it provides a vital tool for undertaking an economically and geologically oriented approach towards exploration.

Here, we have outlined the manner in which the model integrates mining, processing, administrative and infrastructure costs, with a simplified description of the ore-body geometry to determine mining viability. We have also shown how this assessment is extendable to a regional scale by combining the local calculation with maps of regional cover and infrastructure distance. The efficacy of the approach has been demonstrated through regional assessments carried out on mineral deposits and active mines in the Mount Isa region and across the Murray Basin. The results illustrate the potential for this type of analysis to successfully delineate economic-fairways permissive for mining operations.

\section{Acknowledgements}

We gratefully acknowledge the support for this project provided under Geoscience Australia's Exploring for the Future (EFTF) program. We also thank Dr. Gavin Mudd for feedback and advice on the preparation of this manuscript. We acknowledge the traditional custodians of the country where this work was undertaken. We also acknowledge the support provided by individuals, communities as well as state and territory geological surveys which enabled this work. D. Huston and K. Czarnota publish with the permission of the CEO of Geoscience Australia.

Geoscience Australia eCat number: 132645.

\section{Appendix A. Supplementary data}

Supplementary data to this article can be found online at https://doi. org/10.1016/j.resourpol.2020.101598. 


\section{References}

Ali, S.H., Giurco, D., Arndt, N., Nickless, E., Brown, G., Demetriades, A., Durrheim, R., Enriquez, M.A., Kinnaird, J., Littleboy, A., et al., 2017. Mineral supply for sustainable development requires resource governance. Nature 543, 367.

Australian Atlas of Mineral Resources, Mines, \& Processing Centers, 2014. Mineral Processing Plants Dataset.

Australian Bureau of Statistics, 2018. Cat. No. 6427.0 - Producer Price Indexes, Australia, Sep 2018. Table 11. Input to the Coal Mining Industry, Index Numbers and Percentage Changes.

Australian Bureau of Statistics, 2019. 8412.0 - Mineral and Petroleum Exploration, australia march 2019.

Australian Customs and Border Protection Service, 2015. Australian Ports.

Brinsmead, T.S., Hayward, J., Graham, P., 2014. Australian Electricity Market Analysis Report to 2020 and 2030, CSIRO Technical Report No. EP141067.

Burt, K., Lockyer, C., McShane, K., Fong, O.T. (Eds.), 2012. Cost Estimation Handbook, second ed. Australasian Inst. of Mining and Metallurgy. Monograph 27.

Camm, T.W., 1991. Simplified Cost Models for Prefeasibility Mineral Evaluations. US Department of the Interior, Bureau of Mines.

Carter, P.G., 2011. Selection Process for Hard-Rock Mining, SME Mining Engineering Handbook. Society for Mining, Metallurgy, and Exploration, Inc, USA, pp. 357-376.

Curry, J.A., Ismay, M.J., Jameson, G.J., 2014. Mine operating costs and the potential impacts of energy and grinding. Miner. Eng. 56, 70-80.

Deloitte Access Economics, 2017. Mining and METS: Engines of Economic Growth and Prosperity for Australians.

Department of Industry and Science, 2015. Office of the Chief Economist, Resources and Energy Major Projects - Projects Listing.

Dowling, S.E., Hill, R.E., 1998. Komatiite-hosted nickel sulphide deposits, Australia. AGSO J. Aust. Geol. Geophys. 17, 121-128.

Gandhi, S., Sarkar, B., 2016. Chapter 14 - valuation of mineral properties. In: Gandhi, S., Sarkar, B. (Eds.), Essentials of Mineral Exploration and Evaluation. Elsevier, pp. 321-338.

Gao, L., Hou, C., Chen, Y., Barrett, D., Mallants, D., Li, W., Liu, R., 2016. Potential for mine water sharing to reduce unregulated discharge. J. Clean. Prod. 131, 133-144.

Geoscience Australia, 2017a. National Mineral Exploration Strategy 2017-2022. Australia Minerals, p. 8. GA PP-607.

Geoscience Australia, 2017b. Minerals and Petroleum in australia: a Guide for Investors. Geoscience Australia, 2019. Exploring for the future. www.ga.gov.au/eftf.

Gordon, R.B., 2002. Production residues in copper technological cycles. Resour. Conserv. Recycl. 36, 87-106.

Government of Western Australia, 2015. Mineral Royalty Rate Analysis: Final Report.

Groves, D., Foster, R., 1991. Archaean lode gold deposits. In: Gold Metallogeny and Exploration. Springer, pp. 63-103.
Lilford, E.V., Minnitt, R., 2002. Methodologies in the valuation of mineral rights. J. S. Afr. Inst. Min. Metall 102, 369-384.

Lilford, E., Minnitt, R., 2005. A comparative study of valuation methodologies for mineral developments. J. S. Afr. Inst. Min. Metall 105, 29-41.

Long, K.R., 2009. A test and re-estimation of taylor's empirical capacity-reserve relationship. Nat. Resour. Res. 18, 57-63.

Meixner, A., Czarnota, K., Wilford, J., Bonnardot, M.-A., Meixner, T., English, P., Pitt, L., Mathews, E., Thorose, M., Curtis, C., Southby, C., 2019. Depth to Pre-neoproterozoic Rocks between Tennant Creek and Mount Isa: a Preliminary Model.

Mint, Perth, 2019. Precious Metal Refining Process.

Miriam Vale Shire Council, 2007. Engineering Estimates and Financial Implication of Pipeline and Desalination Options for Agnes Water and 1770 (Prepared by Burns Bridge Transactions).

Northey, S.A., Mudd, G.M., Werner, T.T., Haque, N., Yellishetty, M., 2018. Sustainable Water Management and Improved Corporate Reporting in Mining. Water Resources and Industry, p. 100104.

Nourali, H., Osanloo, M., 2019. Mining capital cost estimation using Support Vector Regression (SVR). Resour. Pol. 62, 527-540.

NSW Resources and Energy, 2014. Mining Royalties and Statistics in NSW Guidelines for Compliance Non-coal.

OpenStreetMap contributors, 2018. Planet data retrieved from. https://planet.osm.org. https://www.openstreetmap.org, 2018.

Ports Australia, 2013. Trade Statistics for 2012/2013.

Ports Australia, 2015. Trade Statistics for 2014/2015.

Queensland Government Statistician's Office, 2018. Trade Data - Overseas Exports by Port of Loading, Commodity (3-digit SITC Revision 4) and Country of Destination, Queensland and Australia, 2007-08 to 2017-18 (preliminary).

Reserve Bank of Australia, 2018. Statistical Tables, F11 Exchange Rates.

Senior, A., 2019. Australian Mineral Exploration Review 2017-19, second ed. Geoscience Australia, Canberra. scale 1:10 000000.

State of Queensland, 2013. Mineral Resources Regulation.

State of Tasmania, 2016. Mineral Resources Regulations 2016-41.

Taylor, H., 1977. Mine Valuation and Feasibility Studies. Mineral industry costs. Northwest Min Assoc, WA, Spokane, pp. 1-17.

Tonkin Science Engineering, 2011. Pipeline to the Sea, Feasibility Study phase 1.

Ulrich, S., Trench, A., Hagemann, S., 2019. Grade-cost relationships within australian underground gold mines - a 2014-2017 empirical study and potential value implications. Resour. Pol. 61, 29-48.

UNCOVER group, 2012. Searching the Deep Earth: A Vision for Exploration Geoscience in Australia.

Wilford, J., 2017. Murray Basin Cenozoic Thickness.

Wise, N., Raft, S., 2013. Final Report. Pipeline NSW Program.

Young, Australian, 28 December 2018. In: Company Announcement, 28 December 2018. Young Australian Mines Ltd Obtains US\$2 million funding. 